Journal of Environmental and Agricultural Studies

ISSN: $2710-140$

DOI: $10.32996 /$ jeas

Journal Homepage: www.al-kindipublisher.com/index.php/jeas

\title{
Contribution to Developing an Environmental Emergency Response for Industrial Sites
}

\author{
Adam Abdeljalil ${ }^{1} \square$, Saffaj Nabil ${ }^{2}$ and Mamouni Rachid ${ }^{3}$ \\ ${ }^{123}$ Laboratory of Biotechnology, Materials, and Environment, Faculty of Sciences, University IBN ZOHR, Agadir, Morocco \\ $\square$ Corresponding Author: Adam Abdeljalil, E-mail: adam.abdeljalil@gmail.com
}

\begin{abstract}
ARTICLE INFORMATION
Received: 16 October 2021

Accepted: 25 November 2021

Published: 21 December 2021

DOI: 10.32996/jeas.2021.2.2.9

\section{KEYWORDS}

Emergency, preparedness, environmental damage, industrial site, contractors

\section{ABSTRACT}

This study aims to guarantee that all anticipated emergencies are effectively planned, reviewed, and the necessary equipment and resources are made publicly available to prevent and reduce environmental damage in the event of emergencies for industrial sites. This research aims to ensure that all necessary steps are taken to protect the company's staff, contractors, the environment, neighbouring communities, and assets in the event of a catastrophic leak. It could also serve as a baseline for the industrial site and its subcontractors. Additional measures could be included to improve good practices; The Emergency Preparedness Strategy programs are broad action plans for dealing with situations that may arise at a facility or in the surrounding community. In the event of an emergency at an industrial site, this will allow lives to be saved and property damage to be minimized.
\end{abstract}

\section{Introduction}

The emergency response approach acts as a guide for staff on the industrial sites in responding to situations in a timely and efficient manner. The Emergency response team will follow the appropriate IFC EHS Guidelines, including the "Community Health \& Safety" section. (IFC EHS Guidelines, n.d.)

Environmental emergencies pose a direct threat to human health and the environment's safety. Because of the complexity and urgency of a sudden environmental catastrophe, the key goal of environmental emergency response is to identify and mitigate risks as quickly as possible. When dealing with the environment, a suitable quick-reaction framework can maximize emergency response efficiency by selecting the most effective remedy with the least negative impact and the quickest responsiveness. (Zhao et al., 2021)

The environmental emergency is a complex equation that frequently results in environmental pollutants. Much research is being conducted to build or improve emergency response systems to lessen the dangers and negative consequences of unexpected water contamination events.

The works of (Hu et al., 2021) also developed an innovative model for abrupt water contamination events based on probability analysis and risk calculation. Using the fuzzy logic method, (Li et al., 2019) estimated the general risk ratings based on the environmental standard and the health risk. To control environmental risk,(Penman et al., 2020) employed Bayesian decision network modelling.

Based on the risk study, appropriate emergency management strategies should be selected based on the contaminant category and tailored to various criteria such as the volume and reactivity of contaminants. (Zhang et al., 2011) investigated the causes of various specific environmental problems in industrial sites and the emergency reaction to these occurrences, and discovered that the primary causes are the overzealous drive of rapid urbanization and industrialization and the inappropriate placement of industries. (Shi et al., 2014) developed a four-part emergency disposal approach rating system: pollution source control, pollutant anti-proliferation, pollutant removal, and disposal of old emergency items.

Copyright: (C) 2021 the Author(s). This article is an open access article distributed under the terms and conditions of the Creative Commons Attribution (CC-BY) 4.0 license (https://creativecommons.org/licenses/by/4.0/). Published by Al-Kindi Centre for Research and Development, London, United Kingdom. 
Around the world, in terms of emergency management strategies. The UNEP/OCHA Joint Environment Unit (JEU) has the main potential emergency response system (Environmental Emergency Response., 2020): rapid environmental assessments using the Blink Environmental Evaluation Method (The Flash Environmental Assessment Tool (FEAT), 2020) to evaluate the threats to human health and ecological systems from a sudden emergency, gathering and analysis of air, water, soil, hazardous, and hazardous materials to provide instantaneous dedicated recommendations for appropriate follow-up action.

\section{Methodology}

\subsection{Emergency response team responsibilities}

The following obligations must be followed to properly manage any environmental emergency that may occur on an industrial site:

$>$ Site top Management

- $\quad$ Ascertain that a site-specific Emergency and Preparedness Response Plan is in place, in accordance with business guidelines and appropriate government legislation.

- Ensure that all responding employees and organizations at their site are properly informed about the Emergency and Preparedness Management and Response Plan through rigorous training.

- $\quad$ Responsible for all aspects for completing tasks in accordance with the disaster and preparedness response plan for the location.

$>$ Health, safety and environmental department

- $\quad$ Ensure that the emergency response plan is recorded, implemented, and tested regularly and provided to all appropriate responders and entities.

- $\quad$ To arrive at the emergency and preparedness site as soon as possible after receiving the call or hearing the alert and assist as needed.

- $\quad$ Communicating with the top Management for any necessary assistance.

- $\quad$ Ensure that the IFC EHS Guidelines, including "Community Health \& Safety," are followed.

$>\quad$ Line managers

- $\quad$ To assure their immediate presence during and after emergencies in the emergency and preparedness response operation.

- $\quad$ To support site leaders and help in developing and implementing an emergency and preparedness management and response plan.

- $\quad$ To guarantee that their chosen staff members for the emergency response team receive sufficient training and respond to emergencies as and when required in the absence of the site Emergency team.

- Maintain communication with the top Management, Emergency response team, and Security departments.

$>$ Supervisors and departmental heads

- $\quad$ Along with the site health, safety, and environmental department, prepare, design, and implement a site-specific emergency and preparedness management plan. This will contain all potential industrial scenarios.

- $\quad$ Keep an up-to-date list of all the people who need to be called in case of an emergency or preparedness.

- $\quad$ Ensure that all emergency and preparedness response teams are present during working hours and are accessible on-call during non-working hours.

- $\quad$ Emergency and Preparedness Announcement using available emergency means.

- $\quad$ Oversee the implementation of the emergency and preparedness response plans.

- $\quad$ Oversees the placement of response equipment, among other things.

- $\quad$ The assembly point manager during an environmental incident and evacuation.

- $\quad$ Any unaccounted individuals will be found and recovered by the emergency leaders' search and rescue squad.

- $\quad$ Take command during an exercise, assess whether an emergency or preparedness situation occurs, and start the necessary response and personnel.

- $\quad$ Oversee the planned emergency drill, focused on minimizing harm and business/commercial impact, evacuating workers as needed, alerting and coordinating with external emergency services

D Employees, contractors, visitors, clients 
- $\quad$ Participate in the site emergency instruction training to learn about the Site-Specific Environmental Emergency Response Plan.

- To immediately report any incident, emergency, or crisis to the health, safety, and environmental department by contacting emergency contacts.

\subsection{Emergency response process map}

\section{Environmental emergency preparedness:}

$>$ Perform the risk assessment

$>$ Ensure the competency of the emergency team

$>$ Maintain the availability of emergency equipment

$>$ Maintain emergency contact up to date

$>$ Ensure the effectiveness of communication and training

$>$ Perform regular environmental emergency simulations and drills

$>$ Ensure the maintenance of the site equipment

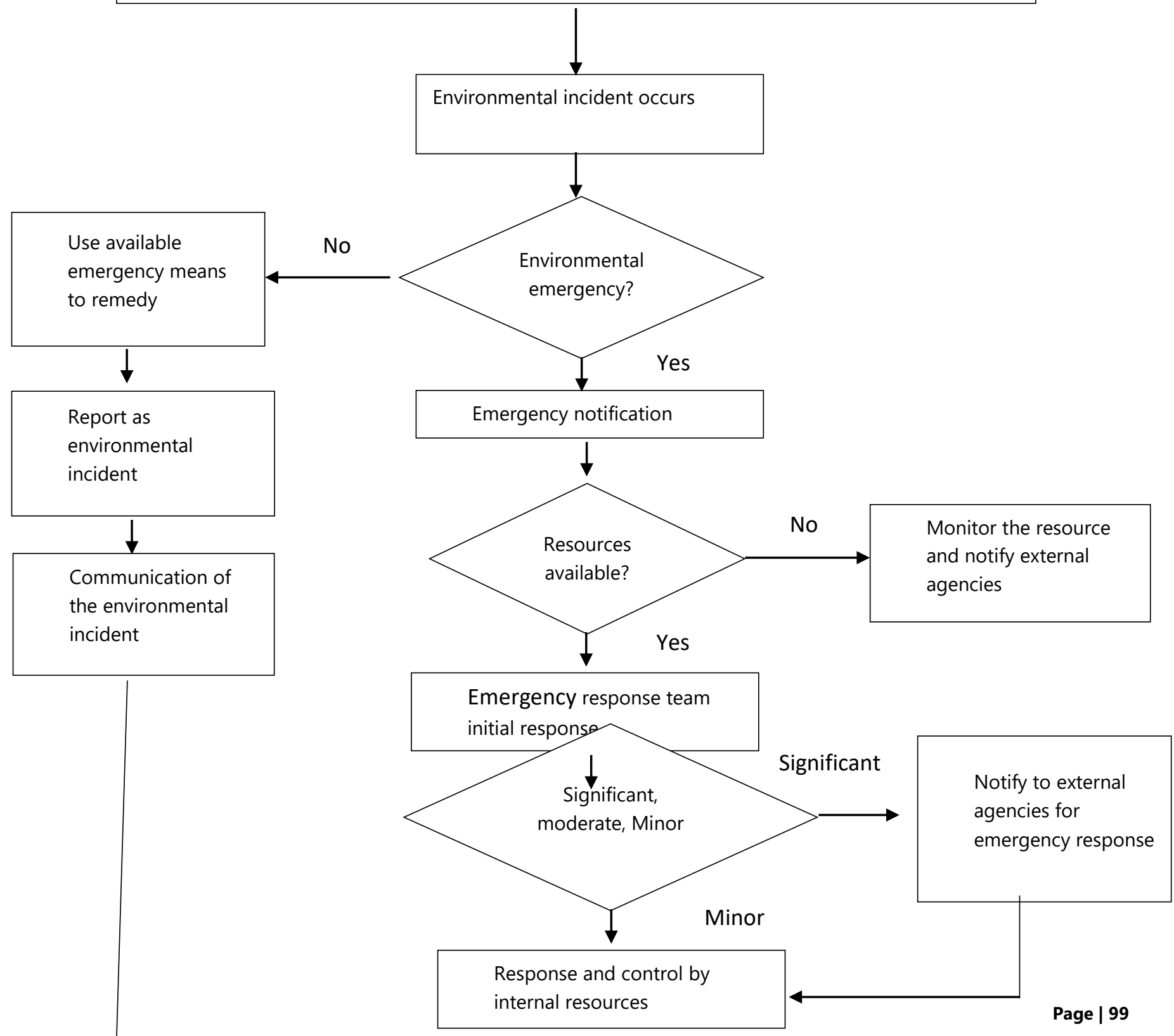




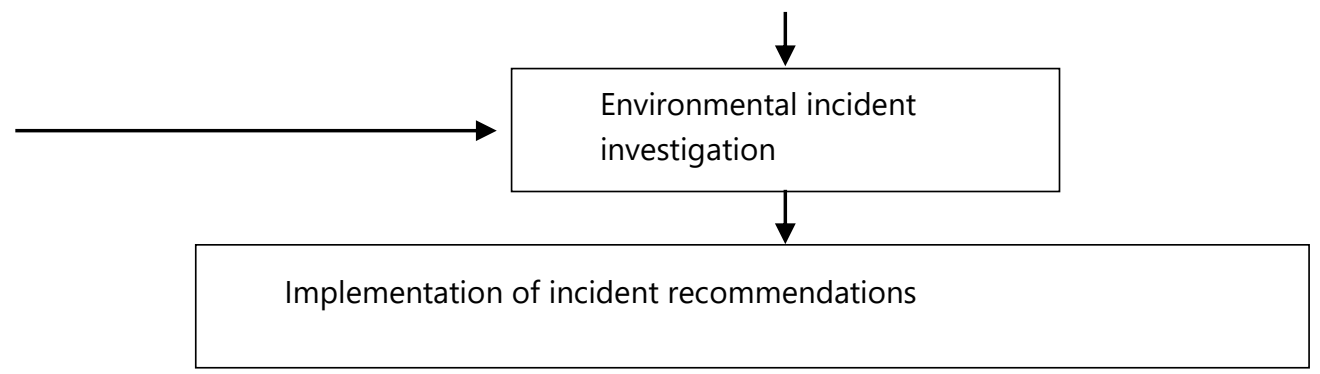

Fig.01: Environmental Emergency response process map

\subsection{Emergency spill and leak.}

The Industrial Emergency Response Plans may emphasize accidental spills/leaks, with the plan serving as a guide for avoiding the consequences of such accidents.

Oil and chemical spills are the most prevalent environmental emergency at industrial sites, and they can lead to soil contamination, groundwater contamination, and water pollution. Hazardous substance spills can include:

- Gasoline

- Diesel

- Hydraulic oil

- Lubricating oil and grease

- Cleaning solvents

- Any other chemical product

The emergency response team should always be established to cover all potential hazards of spills or incidents, and it must be brought to light and accessible to all staff members. Key staff will be able to fully comprehend their roles and coordinate their responses with their subordinates.

This plan will serve as a reference for organizing a quick and effective reaction to oil or chemical spills that affect or are likely to harm the site's region and ensuring preparedness, response, and reporting in the event of an oil or chemical pollution incident. The following precise actions are indicated for this purpose:

- Response

- Reporting

- Preparedness

\subsection{Environmental emergency Preparedness}

The following actions could be useful during the preparedness preparation.

- Guarantee that environmental aspects and impact assessments and hazard identification and risk assessments are carried out on a regular schedule, during organizational change and any general maintenance, and that appropriate controls are in place.

- When selecting an Emergency Response Team (ERT), check that individuals/team members have the requisite competencies and that their qualifications/certificates are up to date and readily available.

- Each employee will complete an initial introduction and training on what to do in the event of a leak.

- Ensure that emergency contacts, equipment locations, and other critical information have been conveyed to all parties involved in the plant.

- The relevant departmental head, in collaboration with the Site Health, safety and Environment department, will ensure that all contractors working in the plant are aware of the emergency process.

- To respond to a chemical or oil leak situation, a range of equipment and personal protective equipment may be required.

The following is a list of equipment:

- Sandbags

- Buckets and shovels

- Storage bins

- Spill kit

- Etc. 
Sand will be dry, and buckets and shovels will be plentiful. Mechanical loading shovels, excavators, and dump trucks may be available for sand distribution and cleanup. All equipment will be housed in a safe position on-site, near the storage and waste areas, in bunded storage containers for contaminated materials and earth, located in the waste storage area and marked and processed as hazardous waste. This material will be utilized to contain and clean up pollution/spills, with special attention paid to dispose of any absorbent materials properly. Stocks will be well-maintained and refilled by the Supervisor and the Environment Coordinator.

\subsection{Environmental emergency Response}

An emergency response can be defined as the measures that should be taken in an emergency.

The following actions will be taken in the event of a chemical or oil spill:

- $\quad$ Notify the top Management and health safety and environment department.

- If the spilt material is flammable, eliminate sources of ignition near the spill area

- Evacuate personnel and neighbours if they are in danger

- Set up a perimeter and create boundary control at a safe distance from the spill.

\section{$>$ Oil or chemical Spill Response Options}

All objects polluted by the oil spill or leakage event must be collected and removed as soon as possible. The following steps must be taken:

- $\quad$ Oil spill kits should be used to collect any residual oil on the ground. The kit should encircle the spill, and then the spill's area should be gradually decreased by enclosing the absorbent. The absorbent pads will absorb the oil. After all the oil on the ground surface has been collected, the absorbent agents must be kept and disposed of properly.

- Contaminated materials must always be treated as hazardous trash. Contaminated items must be collected and kept properly.

- Contaminated goods will be kept in plastic barrels that close tightly. If a concrete-lined bund is available, these barrels should be stored there. A double plastic-lined bund will be employed without such a bund at the site as a short-term storage alternative. Barrels will be placed on plastic or wooden pallets, not directly on the plastic, in the temporary double plastic-lined bund; and Conventional metal barrels cannot be used, even if there are no other options, components may be stored in them if they are covered with plastic cover tightly fastened to prevent Aeolian distribution and stored in an appropriately bunded location to prevent leakage will the barrels suffer corrosion. In-situ cleaning is required for any contaminated materials that cannot be collected and disposed of. This cleaning will be done by a company that has been approved.

\subsection{Incident investigation}

\section{Non-Emergency Spills:}

These spills will be classified as incidents. The department head or area supervisor will conduct an investigation in accordance with each industry's internal Incident Reporting \& Investigation Procedure (where the spill happened).

\section{Emergency Spills:}

In consultation with the investigation team formed by the incident investigation manager, the departmental head and area supervisor (where the spill occurred) will investigate the direct incident cause and root cause per each industry's internal Incident Investigation Procedure and submit the report to the top Management.

\subsection{Reporting}

Anyone working in an industrial setting and sees an environmental incident must report it to the appropriate supervisor. The department of health, safety, and the environment are responsible for ensuring that a report is filed outlining the cause of the incident, the action taken, the incident, and proposed actions to ensure that it does not happen again.

\subsection{Corrective \& Preventive Actions}

Line managers will issue a Non-Conformity Report to the concerned/accountable person for the reported emergency incident. The health, safety, and the environment department will monitor the closure process and provide evidence to the top Management for non-Conformity closure.

\section{Conclusion}

This study aims to guarantee that in the event of an environmental emergency, all required precautions are taken to protect the company's employees, contractors, the environment, surrounding communities, and assets. It might also be used as a benchmark for the industrial site's subcontractors. An emergency response plan for industry lays out methods for dealing with abrupt or 
unpredicted. The goal is to be ready to: Protect lives and damages from occurring, reduce the amount of damage to infrastructure, inventory, and equipment and preserve the people and environment in your neighbourhood, in addition, Restore normal business activities as soon as possible.

Preparation is vital since catastrophes will happen. Many judgments must be taken in a short period when an emergency occurs. Due to time and situation, the conventional chain of command may be unavailable. Furthermore, the incident's stress can lead to bad judgment or significant losses. As a result, preparing and simulating an environmental preparedness plan is essential.

To guarantee that all recognized environmental crises are effectively planned, analyzed, and the necessary equipment and resources are made available to prevent and reduce safety and environmental repercussions in the event of actual emergencies. This research is designed to ensure that in the event of a catastrophic chemical spill or toxic gas release, all required steps are taken to protect Company personnel, contractors, the environment, nearby communities, and assets.

\section{References}

[1] Environmental Emergency Response|. (2020). UNEP-UN Environment Programme. https://www.unenvironment. org/exploretopics/disasters-conflicts/what-we-do/preparedness-and-response/environmental-emergency

[2] Hu, M., Qiu, R. T. R., Wu, D. C., \& Song, H. (2021). Hierarchical pattern recognition for tourism demand forecasting. Tourism Management, 84, 104263. https://doi.org/10.1016/j.tourman.2020.104263

[3] IFC EHS guidelines. (n.d.). International Finance Corporation (IFC). www.ifc.org/ehsguidelines

[4] Li, D., Shi, L., Dong, Z., Liu, J., \& Xu, W. (2019). Risk analysis of sudden water pollution in a plain river network system based on fuzzystochastic methods. Stochastic Environmental Research and Risk Assessment, 33(2), 359-374. https://doi.org/10.1007/s00477-018-01645-z

[5] Penman, T. D., Cirulis, B., \& Marcot, B. G. (2020). Bayesian decision network modelling for environmental risk management: A wildfire case study. Journal of Environmental Management, 270, 110735. https://doi.org/10.1016/j.jenvman.2020.110735

[6] Shi, S., Cao, J., Feng, L., Liang, W., \& Zhang, L. (2014). Construction of a technique plan repository and evaluation system based on AHP group decision-making for emergency treatment and disposal in chemical pollution accidents. Journal of Hazardous Materials, 276, 200206. https://doi.org/10.1016/j.jhazmat.2014.05.034

[7] The Flash Environmental Assessment Tool (FEAT). (2020). 2.0-centre. https://www.eecentre.org/resources/feat/

[8] Zhang, X., Chen, C., Lin, P., Hou, A., Niu, Z., \& Wang, J. (2011). Emergency Drinking Water Treatment during Source Water Pollution Accidents in China: Origin Analysis, Framework and Technologies. Environmental Science \& Technology, 45(1), 161-167. https://doi.org/10.1021/es101987e

[9] Zhao, Y., Pan, Y., Wang, W., \& Guo, L. (2021). A Brain-Inspired Dynamic Environmental Emergency Response Framework for Sudden Water Pollution Accidents. Water, 13(21), 3097. https://doi.org/10.3390/w13213097 